\title{
Effects of isoflavone derivatives on the production of inflammatory cytokines by synovial cells
}

\author{
NUERBIYEMU MIJITI ${ }^{1}$, AKIMASA SOMEYA ${ }^{1}$ and ISAO NAGAOKA ${ }^{1,2}$ \\ ${ }^{1}$ Department of Host Defense and Biochemical Research, Juntendo University, Graduate School of Medicine, Tokyo 113-8421; \\ ${ }^{2}$ Department of Physical Therapy, Faculty of Health Science, Juntendo University, Tokyo 113-0033, Japan
}

Received September 15, 2020; Accepted February 22, 2021

DOI: $10.3892 /$ etm.2021.10735

\begin{abstract}
The present study investigated the effects of isoflavone derivatives (daidzein, genistein and glycitein) on the production of inflammatory cytokines (IL-6 and IL-8) by IL-1 $\beta$-stimulated synovial cells. Synovial MH7A cells were stimulated with IL-1 $\beta$ in the absence or presence of isoflavone derivatives, and IL- 6 and IL- 8 production was measured by ELISA. The results of the present study indicated that daidzein significantly inhibited the production of IL-6, but not IL-8. Conversely, neither genistein nor glycitein exerted any inhibitory effects on the production of IL- 6 or IL- 8 by IL-1 $\beta$-stimulated synovial cells. To elucidate the molecular mechanisms underlying the daidzein-mediated inhibition of IL- 6 production, the present study examined the effects of daidzein on the phosphorylation (activation) of NF- $\kappa \mathrm{B}$ p 65 , ERK1/2 and p38 MAPK. Daidzein significantly inhibited the phosphorylation of $\mathrm{NF}-\kappa \mathrm{B}$ p65 and ERK1/2, but not p38 MAPK in IL-1 $\beta$-stimulated MH7A cells. The present study revealed that among the isoflavone derivatives examined (daidzein, genistein and glycitein), daidzein inhibited the production of IL- 6 , but not IL- 8 , by IL- $1 \beta$-stimulated synovial MH7A cells via the suppression of NF- $\kappa$ B p 65 and ERK1/2 activation. Collectively, these results suggested that daidzein may have potential as a therapeutic agent for the treatment of arthritic disorders through its anti-inflammatory effects via the inhibition of IL-6 production.
\end{abstract}

\section{Introduction}

Activated synovial cells are involved in the pathogenesis and progression of arthritic diseases, such as rheumatoid arthritis and osteoarthritis $(1,2)$. The pro-inflammatory cytokines, tumor necrosis factor (TNF)- $\alpha$ and interleukin (IL)-1 $\beta$, are

Correspondence to: Professor Isao Nagaoka, Department of Physical Therapy, Faculty of Health Science, Juntendo University, 3-2-12 Hongo, Bunkyo, Tokyo 113-0033, Japan

E-mail: nagaokai@juntendo.ac.jp

Key words: isoflavones, daidzein, inflammatory cytokines, synovial cells typical activators of synovial cells (3). They stimulate their own production and also induce the production of other inflammatory cytokines and mediators, including IL-6, IL-8, nitric oxide (NO), and prostaglandin $\mathrm{E}_{2}$, by synovial cells $(4,5)$. Increased levels of these inflammatory cytokines and mediators induce persistent inflammation and cartilage degradation, eventually leading to joint destruction (1). Therefore, the inhibition of inflammatory cytokine and mediator production by activated synovial cells is regarded as a potential therapeutic target for suppressing the progression of inflammation and joint destruction in arthritic diseases (6).

Is of lavone derivatives (isoflavones) are a class of flavonoids that belong to a large family of polyphenolic compounds from plants (such as soybeans, red clover, and kudzu roots) (7-9). Isoflavones are also called phytoestrogens because they contain an estrogen structure (particularly 17 $\beta$-estradiol) (Fig. 1), and mimic the effects of estrogens by binding to estrogen receptors (10-12). Isoflavones are divided into a glycosidic form with sugar chains and an aglycone form without sugar chains in their molecular structures (8). Daidzein, genistein, and glycitein are the aglycone forms of isoflavones (Fig. 1), and exhibit more potent bioactivities than their glycoside forms (10). In addition to estrogenic activity, isoflavones possess various biological properties (such as antioxidant, antimicrobial, and anti-inflammatory activities) (13-15). The anti-inflammatory activities of isoflavones have been examined in detail, and their therapeutic effects have been demonstrated in various animal models with inflammatory disorders, such as lung injury and arthritis $(16,17)$. A previous study confirmed the anti-inflammatory effects of genistein in a collagen-induced rheumatoid arthritis model of rats (17). Genistein, daidzein, and glycitein also exert anti-inflammatory effects through the inhibition of inflammatory cytokine and mediator production by various types of cells, including macrophages, chondrocytes, and synovial cells (18-21). For example, genistein reduced the LPS-stimulated up-regulation of cyclooxygenase (COX)-2 and NO production in primary cultures of human chondrocytes (18). Genistein also decreased the production of IL-1 $\beta$, IL- 6 , and IL- 8 by the TNF- $\alpha$-simulated fibroblast-like synovial cell line MH7A (19). Moreover, daidzein inhibited LPS-stimulated NO and IL-6 production by RAW264.7 mouse macrophage cells (20), and glycitein suppressed NO production by LPS-activated RAW264.7 cells (21). 
We have been investigating the anti-inflammatory effects of various functional food materials, such as glucosamine, citrulline, methionine, and chondroitin sulfate, on IL- 6 and IL- 8 production by IL- $1 \beta$-stimulated synovial cells $(22,23)$, and revealed that these materials inhibit cytokine production by suppressing signaling molecules, including nuclear factor $(\mathrm{NF})-\kappa \mathrm{B}$, extracellular signal regulated kinases (ERK)1/2, and p38 mitogen-activated protein kinase (MAPK). However, the anti-inflammatory effects of isoflavones (daidzein, genistein, and glycitein) on inflammatory cytokine production by IL-1 $\beta$-stimulated synovial cells have not yet been examined. Therefore, the present study investigated the effects of isoflavones (daidzein, genistein, and glycitein) on the production of inflammatory cytokines (IL-6 and IL-8) by IL-1 $\beta$-stimulated synovial cells. The results obtained indicated that among these isoflavones, only daidzein inhibited IL- 6 production by IL-1 $\beta$-stimulated synovial cells, and this effect was mediated by the suppression of NF- $\kappa \mathrm{B}$ and ERK1/2 activation (phosphorylation).

\section{Materials and methods}

Reagents and antibodies. Human IL-1 $\beta$ (cat. no. 200-01B) was purchased from PeproTech; daidzein (cat. no. 09388-64), genistein (cat. no. NH010302), glycitein (cat. no. 09387-74), dimethyl sulfoxide (DMSO; cat. no. 09659-14), RIPA (radioimmunoprecipitation assay) buffer $(50 \mathrm{mmol} / 1$ Tris- $\mathrm{HCl}$ buffer $\mathrm{pH} 7.6,150 \mathrm{mmol} / \mathrm{l} \mathrm{NaCl}, 1 \%$ Nonidet $\mathrm{p} 40$, $0.5 \%$ sodium deoxycholate, $0.1 \%$ SDS (sodium dodecyl sulfate), Protease Inhibitor Cocktail; cat. no. 08714-04), 2X SDS-PAGE (polyacrylamide gel electrophoresis) sample buffer (cat. no. 30657-12), 6X SDS-PAGE sample buffer (cat. no. 09500-64), and WB (western blot) Stripping Solution Strong (cat. no. 05677-65) were from Nacalai Tesque, Inc. A rabbit anti-phosphorylated NF-кB p65 polyclonal antibody (93H1; cat. no. 3033), rabbit anti-phosphorylated ERK1/2 polyclonal antibody (Thr202/Tyr204; cat. no. 9101), rabbit anti-NF-кB p65 (D14E12; cat. no. 8242), and rabbit anti-ERK1/2 (cat. no. 9102) were purchased from Cell Signaling Technology, Inc.; a mouse anti-phosphorylated p38 MAPK monoclonal antibody (clone 30; cat. no. 612281) and mouse anti-p38 MAPK (clone 27; cat. no. 612168) from BD Bioscience Pharmingen; a mouse anti-GAPDH monoclonal antibody (cat. no. MAB374) from Chemicon International; and horseradish peroxidase (HRP)-conjugated goat anti-rabbit immunoglobulin IgG (cat. no. 115-035-144) and HRP-conjugated goat anti-mouse IgG/IgM (cat. no. 115-035-044) from Jackson ImmunoResearch Laboratories, Inc.

Daidzein, genistein, and glycitein were dissolved in DMSO immediately before use, sterilized by filtration, and then used in experiments.

Cell culture. The human fibroblast-like synovial cell line MH7A (RCB1512) obtained from the Riken Cell Bank was cultured in RPMI-1640 medium (Nacalai Tesque, Inc.) supplemented with $10 \%$ fetal bovine serum (FBS; Nichirei Biosciences Inc.), $100 \mathrm{U} / \mathrm{ml}$ penicillin, and $100 \mu \mathrm{g} / \mathrm{ml}$ streptomycin (Nacalai Tesque, Inc.) at $37^{\circ} \mathrm{C}$ in a humidified incubator containing $5 \% \mathrm{CO}_{2}$, as previously described (24).
Measurement of IL- 6 and $I L-8$. MH7A cells were seeded on 24-well culture plates at a density of $3.5 \times 10^{4}$ cells per well and incubated overnight in RPMI-1640 medium containing $10 \%$ FBS. Cells were then pretreated without or with daidzein $(1$ or $5 \mu \mathrm{g} / \mathrm{ml})$, genistein $(1$ or $5 \mu \mathrm{g} / \mathrm{ml})$, and glycitein $\left(1\right.$ or $5 \mu \mathrm{g} / \mathrm{ml}$ ) for $3 \mathrm{~h}$, and stimulated at $37^{\circ} \mathrm{C}$ for $18 \mathrm{~h}$ with or without $50 \mathrm{pg} / \mathrm{ml} \mathrm{IL-1 \beta}$ in a total volume of $0.5 \mathrm{ml}$ RPMI-1640 medium. Thereafter, culture supernatants were collected, centrifuged at $3,600 \times \mathrm{g}$ at $4^{\circ} \mathrm{C}$ for $5 \mathrm{~min}$, and the concentrations of IL-6 and IL-8 in the culture supernatants were assessed by an enzyme-linked immunosorbent assay (ELISA) (R\&D Systems, Inc.) according to the manufacturer's instructions. Briefly, 96-well half area plates were coated with $0.6 \mu \mathrm{g} / \mathrm{ml}$ of the mouse anti-human IL- 6 antibody or $0.7 \mu \mathrm{g} / \mathrm{ml}$ of the mouse anti-human IL-8 antibody diluted in phosphate-buffered saline (PBS; $137 \mathrm{mM} \mathrm{NaCl}$, $2.7 \mathrm{mM} \mathrm{KCl}, 8.1 \mathrm{mM} \mathrm{Na} \mathrm{HPO}_{4}$, and $1.5 \mathrm{mM} \mathrm{KH}_{2} \mathrm{PO}_{4}$; $\mathrm{pH}$ 7.4) and incubated at $4^{\circ} \mathrm{C}$ overnight. The plates were washed three times with PBS containing 0.05\% Tween-20 (PBS-T) and blocked with PBS containing 1\% bovine serum albumin at room temperature for $1 \mathrm{~h}$. Thereafter, plates were washed three times with PBS-T and incubated with culture supernatants or standards $(5-1,000 \mathrm{pg} / \mathrm{ml})$ at room temperature for $2 \mathrm{~h}$. After washing three times with PBS-T, plates were incubated with $15 \mathrm{ng} / \mathrm{ml}$ of the biotinylated goat anti-human IL- 6 antibody or $7 \mathrm{ng} / \mathrm{ml}$ of the biotinylated goat anti-human IL-8 antibody at room temperature for $2 \mathrm{~h}$, washed three times with PBS-T, and then incubated with streptavidin-HRP at room temperature for $30 \mathrm{~min}$. Plates were then washed five times with PBS-T and incubated with tetramethyl benzidine (TMB) liquid substrate at room temperature in the dark until color developed. The reaction was terminated using $1 \mathrm{M} \mathrm{H}_{2} \mathrm{SO}_{4}$ and the absorbance of the solution was measured with a $\mathrm{xMARK}^{\mathrm{TM}}$ Microplate Spectrophotometer (Model 680; Bio-Rad Laboratories, Inc.) at $450 \mathrm{~nm}$.

Phosphorylation of $N F-\kappa B, E R K 1 / 2$, and p38 MAPK. MH7A cells $\left(1.5 \times 10^{5} /\right.$ well $)$ were seeded and cultured in 6 -well plates overnight. Cells were then pretreated without or with $10 \mu \mathrm{g} / \mathrm{ml}$ daidzein for $16 \mathrm{~h}$ and stimulated with $200 \mathrm{pg} / \mathrm{ml} \mathrm{IL-1 \beta}$ at $37^{\circ} \mathrm{C}$ for 15 or $30 \mathrm{~min}$. Cells were washed twice with ice-cold PBS, and then lysed in $150 \mu \mathrm{l} /$ well RIPA buffer containing Phosphatase Inhibitor Cocktail (Roche Diagnostics; cat. no. 04906837 001). Following sonication, lysates were centrifuged at $15,000 \mathrm{x} \mathrm{g}$ at $4^{\circ} \mathrm{C}$ for $15 \mathrm{~min}$ and the supernatants were collected. The protein concentrations of the supernatants were assessed using the Bicinchoninic Acid (BCA) protein assay kit (Pierce Biotechnology), and $12 \mu \mathrm{g}$ protein/lane was used in the western blot analysis. Proteins were separated by $10 \%$ SDS-PAGE and transferred onto an PVDF (polyvinylidene difluoride) membrane (EMD Millipore), followed by blocking with Block Ace solution (Megmilk Snow Brand Co., Ltd.) for $1 \mathrm{~h}$. Membranes were then washed three times with Tris-buffered saline (TBS; $25 \mathrm{mM}$ Tris, $137 \mathrm{mM} \mathrm{NaCl}$, $2.7 \mathrm{mM} \mathrm{KCl}, \mathrm{pH}$ 7.4) containing 0.05\% Tween-20 (TBS-T), and incubated with the rabbit anti-phosphorylated NF- $\mathrm{BB}$ p65 polyclonal antibody (1,000-fold dilution), rabbit anti-phosphorylated ERK1/2 polyclonal antibody (1,000-fold dilution), or mouse anti-phosphorylated p38 MAPK monoclonal antibody 
<smiles>O=c1c(-c2ccc(O)cc2)coc2cc(O)ccc12</smiles>

Daidzein
Genistein<smiles>CC12CCC3c4ccc(O)cc4CCC3C1CCC2O</smiles><smiles>COc1cc2c(=O)c(-c3ccc(O)cc3)coc2cc1O</smiles>

Glycitein

\begin{abstract}
$17 \beta$-Estradiol
Figure 1. Structures of isoflavones (daidzein, genistein, and glycitein) and 17ß-estradiol.
\end{abstract}

(1,000-fold dilution) in TBS containing $0.05 \% \mathrm{NaN}_{3}$ at $4^{\circ} \mathrm{C}$ overnight. After washing three times with TBS-T, the membranes were incubated with HRP-conjugated goat anti-rabbit IgG (5,000-fold dilution) or HRP-conjugated goat anti-mouse $\operatorname{IgG} / \operatorname{IgM}$ (5,000-fold dilution) in TBS containing $10 \%$ Block Ace solution for $1 \mathrm{~h}$. Following washing three times with TBS-T, reactive proteins were detected with SuperSignal ${ }^{\mathrm{TM}}$ West Dura Extended Duration Substrate (Pierce Biotechnology), and signals were quantified using the LAS-3000 luminescent image analyzer (Fujifilm Corporation) and Multi Gauge version 3.0 (Fujifilm Corporation) with the Exposure type of Increment and the View menu of Paint saturated data Red, in which images were analyzed before the saturation of the images.

Membranes were then stripped with WB Stripping Solution Strong for $30 \mathrm{~min}$ and reprobed with rabbit anti-NF- $\kappa \mathrm{B}$ p65 (5,000-fold dilution), rabbit anti-ERK1/2 antibodies (1,000-fold dilution), or mouse anti-p38 MAPK (2,000-fold dilution) followed by an incubation with HRP-conjugated goat anti-rabbit IgG or HRP-conjugated goat anti-mouse IgG/IgM secondary antibodies, respectively.

Glyceraldehyde 3-phosphate dehydrogenase (GAPDH) was detected with a mouse anti-GAPDH monoclonal antibody (50,000-fold dilution; cat. no. MAB374; Chemicon International) and HRP-conjugated goat anti-mouse $\mathrm{IgG} / \mathrm{IgM}$ (5,000-fold dilution).

Reactive proteins were detected and their signals were quantified, as described above.

Statistical analysis. Data were expressed as the mean \pm standard deviation, and analyzed for significant differences by a one-way ANOVA with a post-hoc Tukey's test using GraphPad Prism software version 6.0 (GraphPad Software, Inc.). $\mathrm{P}<0.05$ was considered to indicate a significant difference.

\section{Results}

Effects of daidzein, genistein, and glycitein on IL-6 and IL-8 production by $I L-1 \beta$-stimulated MH7A cells. Fig. 2 shows the effects of daidzein, genistein, and glycitein on IL-6 and IL-8 production by MH7A cells. Cells were stimulated with IL-1 $\beta$ in the absence or presence of daidzein ( 1 or $5 \mu \mathrm{g} / \mathrm{ml}$ ), genistein $(1$ or $5 \mu \mathrm{g} / \mathrm{ml})$, or glycitein ( 1 or $5 \mu \mathrm{g} / \mathrm{ml}$ ) for $18 \mathrm{~h}$, and the levels of IL- 6 and IL- 8 were measured by ELISA. The production of IL-6 (Fig. 2A-C) was approximately 28-fold higher after the IL-1 $\beta$ stimulation $(1,090 \pm 479 \mathrm{pg} / \mathrm{ml})$ than that by unstimulated cells $(38 \pm 35 \mathrm{pg} / \mathrm{ml})$. Daidzein $(5 \mu \mathrm{g} / \mathrm{ml})$ markedly inhibited the production of IL- 6 by approximately $20 \%$ from that by the IL- $1 \beta$ stimulation $(\mathrm{P}=0.3$ compared with IL-1 $\beta$ stimulation + DMSO, and $\mathrm{P}=0.1$ compared with IL-1 $\beta$ stimulation only), whereas $1 \mu \mathrm{g} / \mathrm{ml}$ daidzein did not significantly affect IL-6 production (Fig. 2A). On the other hand, genistein and glycitein did not exert any significant effects on IL-6 production in IL-1 $\beta$-stimulated MH7A cells (Fig. 2B and $\mathrm{C}$ ). Furthermore, the production of IL-8 was approximately 127 -fold higher with the IL-1 $\beta$ stimulation $(2,359 \pm 1,206 \mathrm{pg} / \mathrm{ml})$ than that by unstimulated cells $(19 \pm 33 \mathrm{pg} / \mathrm{ml})$. However, neither daidzein, genistein, nor glycitein exerted any significant effects on IL-8 production (Fig. 2D-F).

A morphological analysis of the cytotoxic effects of daidzein on IL-1 $\beta$-stimulated human synovial MH7A cells was performed under light microscopy. Daidzein did not induce cell death (such as apoptosis and necrosis) in IL-1 $\beta$-stimulated MH7A cells during an incubation at 5 and $10 \mu \mathrm{g} / \mathrm{ml}$ (data not shown). Consistent with this result, similar amounts of GAPDH, an internal control, were recovered from the cell lysates of unstimulated MH7A cells, IL-1 $\beta$-stimulated MH7A cells, and IL-1 $\beta$-stimulated MH7A cells incubated with daidzein (Figs. 3 and 4). 
A

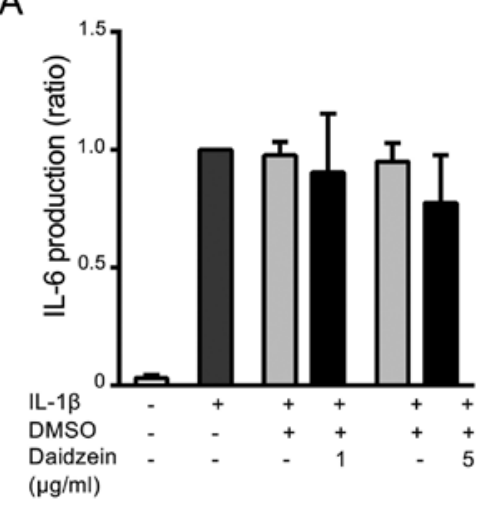

B

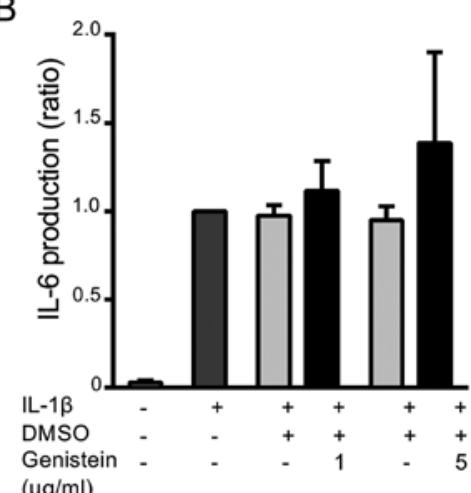

C

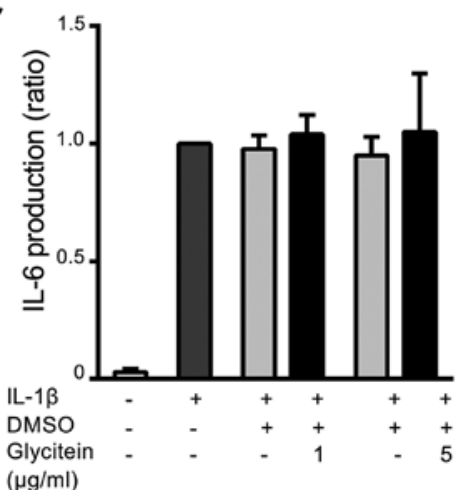

D

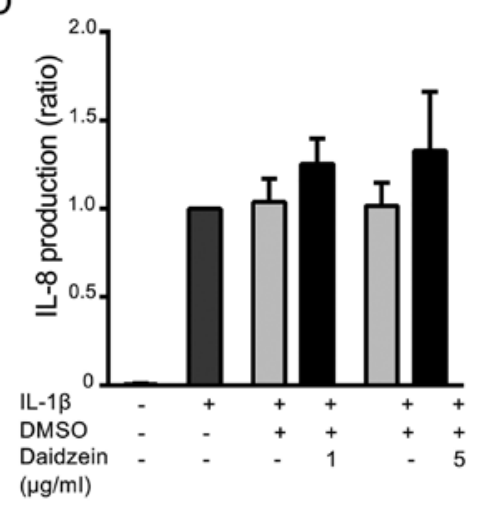

E

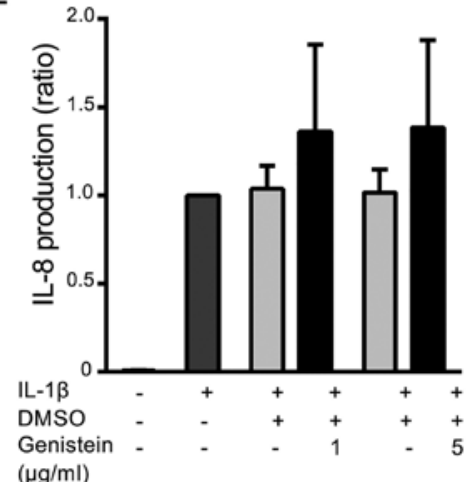

F

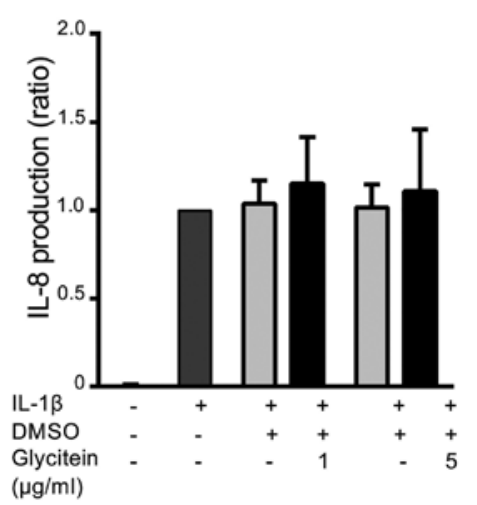

Figure 2. Effects of daidzein, genistein, and glycitein on IL-6 and IL-8 production by IL-1 $\beta$-stimulated MH7A cells. Cells were treated without (-) or with (+) 1 or $5 \mu \mathrm{g} / \mathrm{ml}$ of (A and D) daidzein, (B and E) genistein or (C and F) glycitein for $3 \mathrm{~h}$, and then stimulated without (-) or with (+) $50 \mathrm{pg} / \mathrm{ml} \mathrm{IL}-1 \beta$ for $18 \mathrm{~h}$. Alternatively, cells were treated without (-) or with (+) $0.5 \%$ DMSO (a solvent of isoflavones) in the absence of isoflavones, and then stimulated with IL-1 3 . Thereafter, culture supernatants were recovered, and (A-C) IL-6 and (D-F) IL-8 levels were measured by ELISA. Data are expressed as a ratio to that in IL-1 $\beta$-stimulated MH7A cells without isoflavone derivatives, and compared between without and with isoflavones. Results are shown as the means \pm SD of five independent experiments. DMSO, dimethyl sulfoxide.

Effects of daidzein on the phosphorylation of $N F-\kappa B, E R K 1 / 2$, and $p 38 M A P K$. The activation of the NF- $\kappa \mathrm{B}$ and MAPK (ERK1/2 and p38 MAPK) signaling pathways is involved in the production of inflammatory cytokines. Therefore, to elucidate the mechanisms underlying the daidzein-mediated suppression of IL- 6 production, we examined the activation (phosphorylation) of NF- $\mathrm{B}$ p65, ERK1/2, and p38 MAPK. MH7A cells were stimulated with $200 \mathrm{pg} / \mathrm{ml}$ IL-1 $\beta$ for 15 or $30 \mathrm{~min}$ after the treatment with or without $10 \mu \mathrm{g} / \mathrm{ml}$ daidzein for $16 \mathrm{~h}$. The phosphorylation of $\mathrm{NF}-\kappa \mathrm{B}$ p65, ERK1/2, and p38 MAPK was evaluated by western blotting. When cells were stimulated with IL-1 $\beta$ for $15 \mathrm{~min}$, the phosphorylation of $\mathrm{NF}-\kappa \mathrm{B}$ p65 was approximately 17-fold higher (Fig. 3A) than that in unstimulated cells. Daidzein $(10 \mu \mathrm{g} / \mathrm{ml})$ significantly inhibited the phosphorylation of $\mathrm{NF}-\kappa \mathrm{B}$ p 65 by $23 \%$ from that by the IL-1 $\beta$ stimulation only (Fig. 3A). The phosphorylation of ERK1/2 and p38 MAPK was also increased by approximately 1.7 - and 5-fold, respectively, by the IL-1 $\beta$ stimulation (Fig. 3B and C). However, daidzein $(10 \mu \mathrm{g} / \mathrm{ml})$ did not show exert any significant effects on the phosphorylation of ERK1/2 or p38 MAPK (Fig. 3B and C).

We also examined the effects of daidzein $(10 \mu \mathrm{g} / \mathrm{ml})$ on the phosphorylation of NF- $\kappa \mathrm{B}$ p65, ERK1/2, and p38 MAPK after the stimulation with IL-1 $\beta$ for 30 min. After the stimulation, the phosphorylation of NF- $\kappa \mathrm{B}$ p65, ERK1/2, and p38 MAPK was approximately 23-, 2-, and 2.6-fold higher, respectively, that that in unstimulated cells (Fig. 4). Daidzein $(10 \mu \mathrm{g} / \mathrm{ml})$ significantly inhibited the IL-1 $\beta$-induced phosphorylation 
A

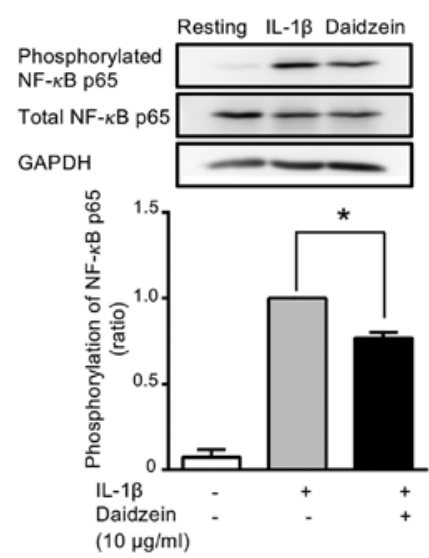

B

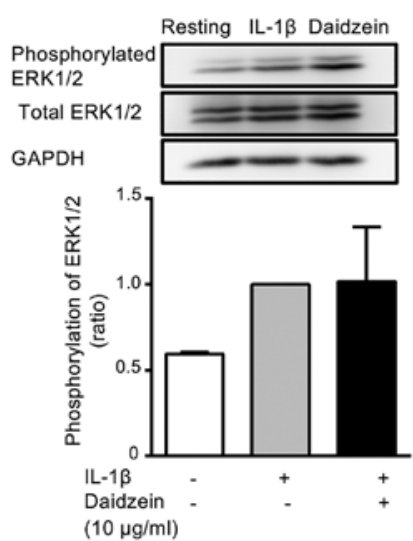

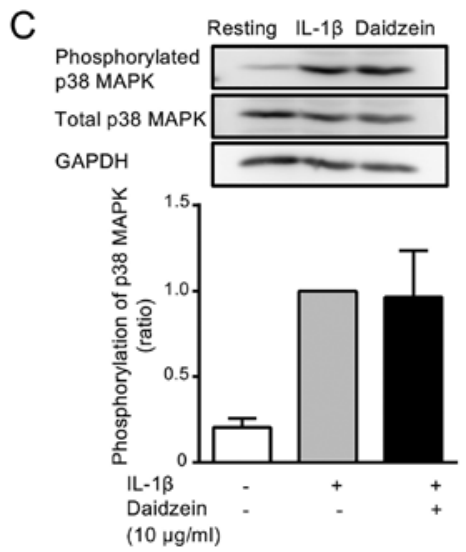

Figure 3. Effects of daidzein on the phosphorylation of NF- $\mathrm{BB}, \mathrm{ERK} 1 / 2$, and p38 MAPK. Cells were treated without (-) or with (+) $10 \mu \mathrm{g} / \mathrm{ml}$ daidzein for $16 \mathrm{~h}$, and then stimulated without (-) or with (+) $200 \mathrm{pg} / \mathrm{ml} \mathrm{IL-1 \beta}$ for $15 \mathrm{~min}$. Cells were harvested, the supernatants (containing $12 \mu \mathrm{g}$ protein) obtained from cell lysates were resolved on $10 \%$ SDS-PAGE, and phosphorylated and total (A) NF- $\mathrm{B}$ p65, (B) ERK1/2 and (C) p38 MAPK were evaluated by western blotting. GAPDH (an internal control) was also detected by western blotting. Images are representative of three separate experiments. The phosphorylation of NF- $\mathrm{B}$ p 65, ERK1/2, and p38 MAPK was normalized with total NF- $\kappa \mathrm{B}$ p65, ERK1/2, and p38 MAPK, respectively, and expressed as a ratio to that in IL-1 $\beta$-stimulated MH7A cells without daidzein. Data were compared between without and with daidzein. Results are expressed as the means \pm SD of three independent experiments. ${ }^{*} \mathrm{P}<0.05$. NF- $\kappa \mathrm{B}$, nuclear factor- $\kappa \mathrm{B}$; ERK, extracellular signal regulated kinases; p38 MAPK, p38 mitogen-activated protein kinase.

of ERK1/2 by $50 \%$ (Fig. 4B). In contrast, daidzein did not exert any significant effects on the phosphorylation of $\mathrm{p} 65$ or p38 MAPK after the 30-min stimulation (Fig. 4A and C).

Therefore, daidzein inhibited the IL-1 $\beta$-induced phosphorylation of NF- $\kappa$ B p65 (after $15 \mathrm{~min}$ ) and ERK1/2 (after $30 \mathrm{~min})$ in $\mathrm{MH} 7 \mathrm{~A}$ cells.

\section{Discussion}

The present study investigated the effects of isoflavone derivatives (daidzein, genistein, and glycitein) on the production of inflammatory cytokines (IL-6 and IL-8) by IL-1 $\beta$-stimulated synovial MH7A cells. The results obtained indicated that daidzein markedly inhibited the production of IL-6, but not IL-8. In contrast, neither genistein nor glycitein exerted any effects on IL- 6 or IL- 8 production by IL-1 $\beta$-stimulated synovial cells.

A previous study reported that genistein significantly inhibited the production of IL- 6 and IL- 8 by TNF- $\alpha$ stimulated synovial MH7A cells (19). However, in the present study, genistein did not inhibit the production of IL-6 or IL-8 by IL-1 $\beta$-stimulated synovial MH7A cells. Therefore, genistein may exert different effects on cytokine production depending on the stimuli used (different stimuli of IL-1 $\beta$ and TNF- $\alpha$ ).
In addition, the present study indicated that glycitein did not affect IL- 6 or IL- 8 production by IL-1 $\beta$-stimulated synovial cells. To the best of our knowledge, the effects of glycitein on cytokine production have not yet been examined.

The signal transduction pathways of $N F-\kappa B$ and MAPK (ERK1/2 and p38 MAPK) play a critical role in the production of inflammatory cytokines and mediators (25-27). Therefore, to elucidate the molecular mechanisms underlying the daidzein-mediated inhibition of IL-6 production, we examined the effects of daidzein on the phosphorylation (activation) of NF- $\kappa \mathrm{B}$ p65, ERK1/2, and p38 MAPK. The results obtained indicated that daidzein significantly inhibited the phosphorylation of $\mathrm{NF}-\kappa \mathrm{B}$ p65 (15 min) and ERK1/2 (30 min) by MH7A cells after the IL- $1 \beta$ stimulation. In contrast, daidzein did not exert any effects on the phosphorylation of p38 MAPK. A previous study reported that daidzein inhibited the phosphorylation of $\mathrm{NF}-\kappa \mathrm{B}$ p65 in lipopolysaccharide (LPS)-stimulated murine J774 macrophages (28). However, the effects of daidzein on the phosphorylation of ERK1/2 currently remain unknown. Following the IL-1 $\beta$ stimulation, TAK1 (transforming growth factor- $\beta$-activated kinase 1 ; an isoform of MAP kinase kinase kinase; MAPKKK) was shown to be activated, and activated TAK1 phosphorylated the inhibitor of $\kappa \mathrm{B}$ (IкB) kinase (IKK) (Fig. 5) $(4,29,30)$. Activated IKK phosphorylates I $\mathrm{B}$ in the 
A

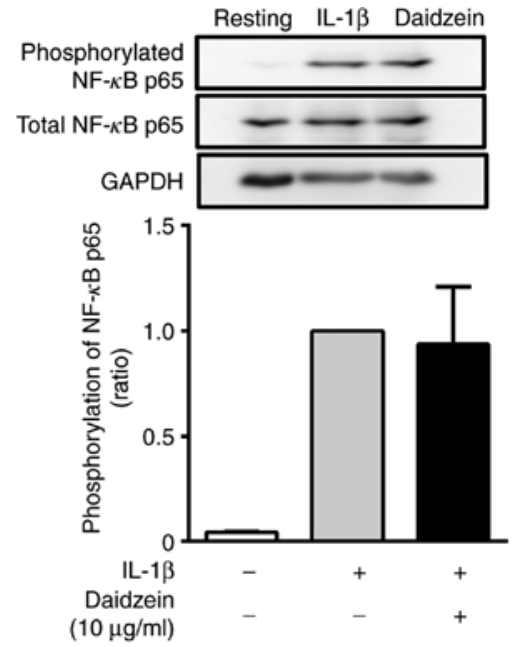

B
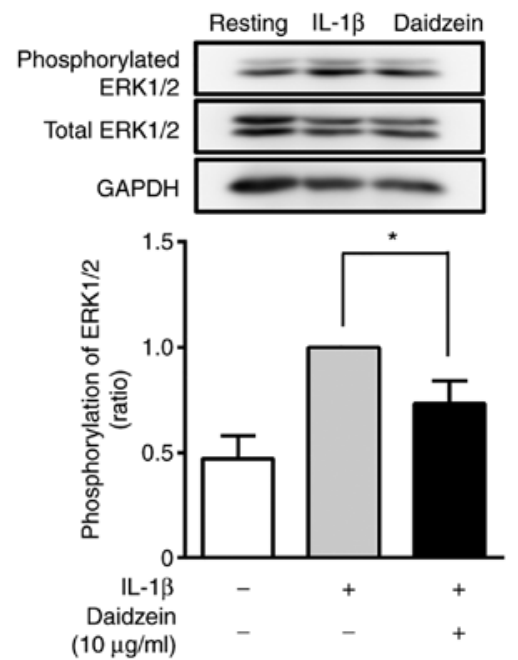

C

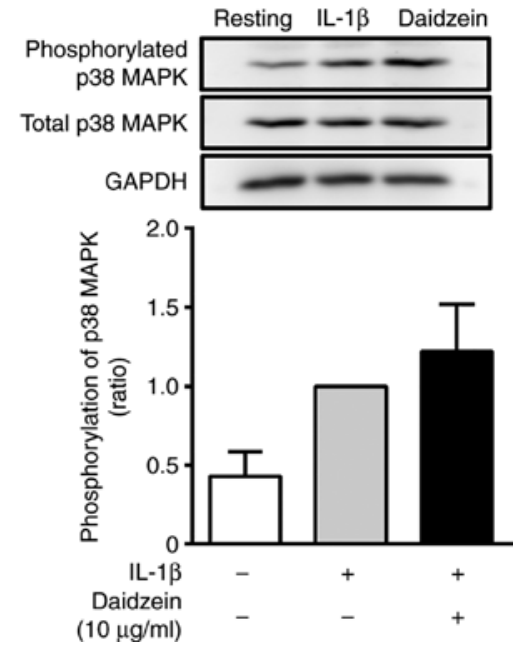

Figure 4. Effects of daidzein on the phosphorylation of NF-kB, ERK1/2, and 38 MAPK. Cells were treated without (-) or with (+) $10 \mu \mathrm{g} / \mathrm{ml}$ daidzein for $16 \mathrm{~h}$ and then stimulated without (-) or with $(+) 200 \mathrm{pg} / \mathrm{ml} \mathrm{IL}-1 \beta$ for $30 \mathrm{~min}$. Thereafter, cells were harvested, the supernatants (containing $12 \mu \mathrm{g}$ protein) obtained from cell lysates were resolved on 10\% SDS-PAGE, and phosphorylated and total (A) NF-кB p65, (B) ERK1/2 and (C) p38 MAPK were evaluated by western blotting. GAPDH (an internal control) was also detected by western blotting. Images are representative of three separate experiments. The phosphorylation of NF-kB p65, ERK1/2, and p38 MAPK was normalized to total NF- $\mathrm{BB}$ p65, ERK1/2, and p38 MAPK, respectively, and expressed as a ratio to that in IL-1 $\beta$-stimulated MH7A cells without daidzein. Data are compared between without and with daidzein. Results are expressed as the means $\pm \mathrm{SD}$ of three independent experiments. ${ }^{*} \mathrm{P}<0.05$. NF- $\kappa B$, nuclear factor- $\kappa \mathrm{B}$; ERK, extracellular signal regulated kinases; p38 MAPK, p38 mitogen-activated protein kinase.

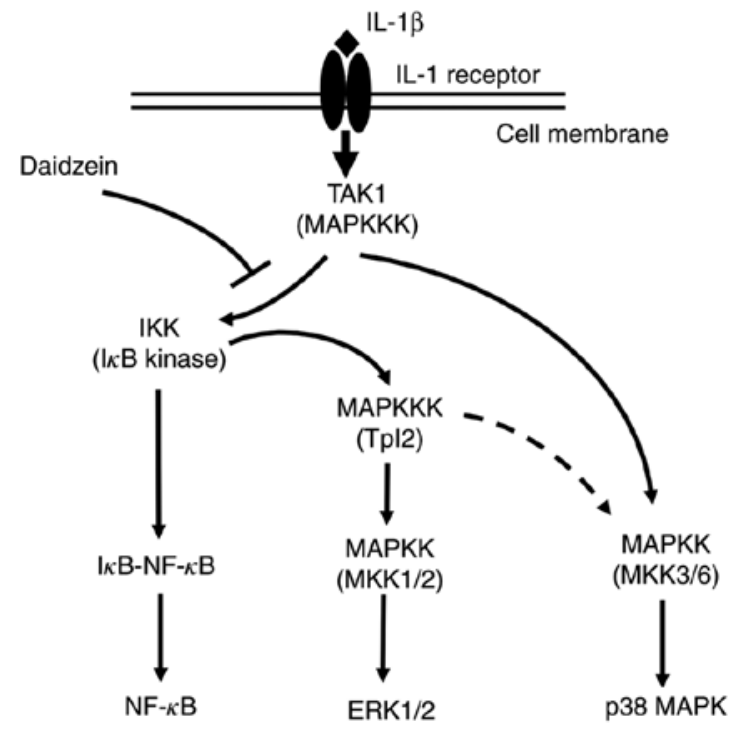

Figure 5. Schematic model of IL-1 $\beta$-stimulated signaling pathways of NF- $\mathrm{kB}$ p65, ERK1/2, and 338 MAPK, and inhibitory effects of daidzein on $\mathrm{NF}-\kappa \mathrm{B} / \mathrm{ERK} 1 / 2$ signaling in synovial cells. TAK1 is activated by a stimulation with IL-1 $\beta$, and activated TAK1 phosphorylates the IKK. Activated IKK

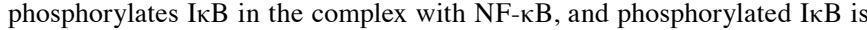
degraded by the ubiquitin-proteasome system, which allows the release and nuclear translocation of NF- $\mathrm{\kappa B}$, leading to the transcription of inflammatory cytokine genes. Moreover, activated IKK activates Tpl2, which, in turn, activates MKK1/2, leading to the activation of ERK1/2. Alternatively, TAK1 activates the p38 MAPK pathway via the activation of MKK3 and MKK6. p38 MAPK may also be activated by TAK1 via the IKK/Tp12 pathway (dotted line). Since daidzein inhibited the phosphorylation of NF- $\mathrm{\kappa B}$ p65 and ERK1/2, but not p38MAPK in IL-1 $\beta$-stimulated MH7A cells, it appears to inhibit the TAK1/IKK-mediated activation of NF- $\mathrm{kB}$ p 65 and ERK1/2, but not the TAK1/MKK3/MKK6-mediated activation of p38 MAPK. IKK, ІкB

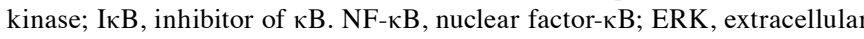
signal regulated kinases; p38 MAPK, p38 mitogen-activated protein kinase; TAK1, transforming growth factor- $\beta$-activated kinase 1; MAPKKK, MAP

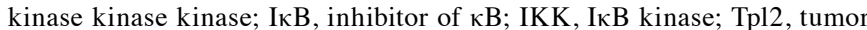
progression locus 2; MKK and MAPKK, mitogen-activated protein kinase kinase.

complex with NF- $\kappa \mathrm{B}$, and phosphorylated I $\mathrm{B}$ is degraded by the ubiquitin-proteasome system, which allows the release and nuclear translocation of NF- $\mathrm{KB}$, leading to the transcription of inflammatory cytokine genes (Fig. 5) (29-32). Moreover, activated IKK activates Tpl2 (tumor progression locus 2; an isoform of MAPKKK), which, in turn, activates MKK (mitogen-activated protein kinase kinase; MAPKK) $1 / 2$, leading to the activation of ERK1/2 (Fig. 5) (33). Alternatively, TAK1 activates the p38 MAPK pathway via the activation of MKK3 and MKK6 (33). p38 MAPK may also be activated by TAK1 via the IKK/Tpl2 pathway (33). The present study revealed that daidzein inhibited the phosphorylation of NF- $\kappa \mathrm{B}$ p65 and ERK1/2 (Figs. 3A and 4B), but not p38MAPK in IL-1 $\beta$-stimulated MH7A cells. Therefore, it is reasonable to speculate that daidzein primarily inhibits the TAK1/IKK-mediated activation of NF-kB p65 and ERK1/2, but not the TAK1/MKK3/MKK6-mediated activation of p38 MAPK. Moreover, daidzein significantly inhibited the phosphorylation of NF-kB p65 (15 min) and ERK1/2 (30 min) by MH7A cells after the IL-1 $\beta$ stimulation. The time difference in the inhibitory effects of daidzein on the phosphorylation of NF- $\mathrm{KB}$ p65 (15 min) and ERK1/2 (30 min) may reflect differences in the activation of NF- $\mathrm{kB}$ p65 (activation at an early 
stage) and ERK1/2 (activation at a later stage) via the different signal transduction pathways starting from TAK1 by the IL-1 $\beta$ stimulation in MH7A cells.

$\mathrm{NF}-\kappa \mathrm{B}$ is a pivotal transcription factor for the expression of inflammatory cytokines, such as IL-6 and IL-8 $(25,34)$. After its stimulation, $\mathrm{NF}-\kappa \mathrm{B}$ translocates to the nucleus and binds to the NF- $\kappa \mathrm{B}$ binding site of the promoters for cytokine genes, leading to cytokine gene expression (35-37). In the present study, daidzein significantly inhibited the phosphorylation of NF- $\mathrm{B}$ p65 (Fig. 3A) and production of IL-6 (Fig. 2A), but not IL-8 (Fig. 2D). IL-6 production was approximately 28 -fold higher after the IL-1 $\beta$ stimulation than that by unstimulated cells, whereas IL- 8 production was increased by approximately 127 -fold by the IL- $1 \beta$ stimulation. Daidzein inhibited the phosphorylation of NF- $\mathrm{B}$ p65 by only $20 \%$ (Fig. 3A). Therefore, the expression of IL- 6 appears to be more sensitive to the inhibitory effects of daidzein than that of IL-8, and the weak daidzein-induced inhibition of NF- $\mathrm{NB}$ p65 phosphorylation (approximately 20\%) may suppress the moderate elevations in IL-6 expression, but not the marked increases in IL-8 expression. However, further studies are needed to clarify the mechanisms responsible for the different effects of daidzein on IL-6 and IL-8 production.

In the present study, the concentrations of daidzein (5 and $10 \mu \mathrm{g} / \mathrm{ml})$ and the incubation periods with daidzein (3 and $16 \mathrm{~h})$ are different between ELISA (detection of cytokines IL-6 and IL-8) and western blot analysis (detection of the phosphorylation of NF- $\kappa \mathrm{B}, \mathrm{ERK} 1 / 2$ and p38 MAPK). This is based on the facts that the detection of cytokines by ELISA is highly sensitive. Thus, cytokine production was markedly increased by a low concentration of IL-1 $\beta$ (50 pg/ml), and especially IL-6 production was significantly suppressed by incubation with $5 \mu \mathrm{g} / \mathrm{ml}$ daidzein for $3 \mathrm{~h}$ (as shown in Fig. 2A). In contrast, the detection of the phosphorylation of NF- $\mathrm{KB}, \mathrm{ERK} 1 / 2$ and p38 MAPK was low-sensitive, and the phosphorylation was significantly enhanced by a high concentration of IL-1 $\beta$ (200 pg/ml). Thus, to make the suppressive effect of daidzein more effective, MH7A cells were incubated with a high concentration of daidzein $(10 \mu \mathrm{g} / \mathrm{ml})$ for a long period $(16 \mathrm{~h})$ to detect the effect of daidzein on the phosphorylation of NF- $\mathrm{B}$, ERK1/2 and p38 MAPK (Figs. 3 and 4), compared with the effect of daidzein on cytokine production $(5 \mu \mathrm{g} / \mathrm{ml}$ daidzein and incubation period $3 \mathrm{~h}$ ) (Fig. 2).

In conclusion, the present study revealed that among the isoflavone derivatives examined (daidzein, genistein, and glycitein), daidzein inhibited the production of IL-6, but not IL- 8 by IL-1 $\beta$-stimulated synovial MH7A cells, possibly via the suppression of NF- $\mathrm{NB}$ p 65 and ERK1/2 activation. IL-6 is a pleiotropic cytokine that plays a pivotal role in the pathophysiology of arthritis, which is found in the synovial fluid, and its level correlates with disease activity and joint destruction (38). Furthermore, IL-6 may promote synovitis and joint destruction by stimulating neutrophil migration, osteoclast maturation, and vascular endothelial growth factor (VEGF)-stimulated pannus proliferation (38). In contrast, IL-8 is an inflammatory chemokine that is involved in the pathological processes of arthritis, including the release of matrix metalloproteinase-13 (MMP-13), neutrophil accumulation, and leukocyte homing to the synovium (39). Based on these findings, daidzein has potential as a therapeutic agent for arthritic disorders by mainly suppressing IL-6 production, thereby ameliorating the progression of inflammation and joint destruction.

\section{Acknowledgements}

The authors would like to thank Dr Keiji Miyazawa (Kissei Pharmaceutical Co., Ltd., Nagano, Japan) for the establishment of MH7A cells, and Dr Mamoru Igarashi, Dr Kaori Suzuki, Dr Taisuke Murakami and Dr Yumi Kumagai Department of Host Defense and Biochemical Research, Juntendo University, Graduate School of Medicine, for their technical assistance and helpful discussions.

\section{Funding}

No funding was received.

\section{Availability of data and materials}

The datasets used and/or analyzed during the current study are available from the corresponding author on reasonable request.

\section{Authors' contributions}

NM substantially contributed to the conception and design of this study, and the acquisition of data. AS and IN confirmed the authenticity of all the raw data. NM, AS and IN were involved in the analysis and interpretation of data, and drafting and revising the manuscript for important intellectual content. All authors read and approved the final manuscript.

\section{Ethics approval and consent to participate}

Not applicable.

\section{Patient consent for publication}

Not applicable.

\section{Competing interests}

The authors declare that they have no competing interests.

\section{References}

1. Huber LC, Distler O, Tarner I, Gay RE, Gay S and Pap T: Synovial fibroblasts: Key players in rheumatoid arthritis. Rheumatol (Oxford) 45: 669-675, 2006.

2. Mathiessen A and Conaghan PG: Synovitis in osteoarthritis: Current understanding with therapeutic implications. Arthritis Res Ther 19: 18, 2017.

3. Storch H, Zimmermann B, Resch B, Tykocinski LO, Moradi B, Horn P, Kaya Z, Blank N, Rehart S, Thomsen M, et al: Activated human B cells induce inflammatory fibroblasts with cartilage-destructive properties and become functionally suppressed in return. Ann Rheum Dis 75: 924-32, 2016.

4. Wojdasiewicz P, Poniatowski ŁA and Szukiewicz D: The role of inflammatory and anti-inflammatory cytokines in the pathogenesis of osteoarthritis. Mediators Inflamm 2014: 561459, 2014.

5. Pelletier JP, Martel-Pelletier J and Abramson SB: Osteoarthritis, an inflammatory disease: Potential implication for the selection of new therapeutic targets. Arthritis Rheum 44: 1237-1247, 2001. 
6. Malemud CJ: Biologic basis of osteoarthritis: State of the evidence. Curr Opin Rheumatol 27: 289-294, 2015.

7. Barnes S, Prasain J, D'Alessandro T, Arabshahi A, Botting N, Lila MA, Jackson G, Janle E and Weaver CM: The metabolism and analysis of isoflavones and other dietary polyphenols in foods and biological systems. Food Funct 2: 235-244, 2011.

8. Barnes S: The biochemistry, chemistry and physiology of the isoflavones in soybeans and their food products. Lymphat Res Biol 8: 89-98, 2010.

9. Beck V, Rohr U and Jungbauer A: Phytoestrogens derived from red clover: An alternative to estrogen replacement therapy? J Steroid Biochem Mol Biol 94: 499-518, 2005.

10. Munro IC, Harwood M, Hlywka JJ, Stephen AM, Doull J, Flamm WG and Adlercreutz H: Soy isoflavones: A safety review. Nutr Rev 61: 1-33, 2003.

11. Vitale DC, Piazza C, Melilli B, Drago F and Salomone S: Isoflavones: Estrogenic activity, biological effect and bioavailability. Eur J Drug Metab Pharmacokinet 38: 15-25, 2013.

12. Morito K, Hirose T, Kinjo J, Hirakawa T, Okawa M, Nohara T, Ogawa $\mathrm{S}$, Inoue $\mathrm{S}$, Muramatsu $\mathrm{M}$ and Masamune $\mathrm{Y}$ : Interaction of phytoestrogens with estrogen receptors alpha and beta. Biol Pharm Bull 24: 351-356, 2001.

13. Rodriguez-Roque MJ, Rojas-Grau MA, Elez-Martinez P and Martin-Belloso O: Soymilk phenolic compounds, isoflavones and antioxidant activity as affected by in vitro gastrointestinal digestion. Food Chem 136: 206-212, 2013.

14. Chacko BK, Chandler RT, D'Alessandro TL, Mundhekar A, Khoo NK, Botting N, Barnes S and Patel PP: Anti-inflammatory effects of isoflavones are dependent on flow and human endothelial cell PPARgamma. J Nutr 137: 351-356 2007.

15. Hong H, Landauer MR, Foriska MA and Ledney GD Antibacterial activity of the soy isoflavone genistein. J Basic Microbiol 46: 329-335, 2006.

16. Kang JL, Lee HW, Lee HS, Pack IS, Chong Y, Castranova V and Koh Y: Genistein prevents nuclear factor-kappa B activation and acute lung injury induced by lipopolysaccharide. Am J Respir Crit Care Med 164: 2206-2212, 2001.

17. Verdrengh M, Jonsson IM, Holmdahl R and Tarkowski A: Genistein as an anti-inflammatory agent. Inflamm Res 52 : 341-346, 2003

18. Hooshmand S, Soung do Y, Lucas EA, Madihally SV, Levenson CW and Arjmandi BH: Genistein reduces the production of proinflammatory molecules in human chondrocytes. J Nutr Biochem 18: 609-614, 2007.

19. Li J, Li J, Yue Y, Hu Y, Cheng W, Liu R, Pan X and Zhang P: Genistein suppresses tumor necrosis factor alpha-induced inflammation via modulating reactive oxygen species/Akt/nuclear factor $\kappa \mathrm{B}$ and adenosine monophosphate-activated protein kinase signal pathways in human synoviocyte MH7A cells. Drug Des Devel Ther 8: 315-323, 2014.

20. Choi EY, Jin JY, Lee JY, Choi JI, Choi IS and Kim SJ: Anti-inflammatory effects and the underlying mechanisms of action of daidzein in murine macrophages stimulated with Prevotella intermedia lipopolysaccharide. J Periodontal Res 47: 204-211, 2012

21. Sheu F, Lai HH and Yen GC: Suppression effect of soy isoflavones on nitric oxide production in RAW 264.7 macrophages. J Agric Food Chem 49: 1767-1772, 2001.

22. Yamagishi Y, Someya A, Imai K, Nagao J and Nagaoka I: Evaluation of the anti-inflammatory actions of various functional food materials including glucosamine on synovial cells. Mol Med Rep 16: 1353-1359, 2017.
23. Yamagishi Y, Someya A and Nagaoka I: Citrulline cooperatively exerts an anti-inflammatory effect on synovial cells with glucosamine and N-acetylglucosamine. Biomed Rep 13: 37-42, 2020.

24. Someya A, Ikegami T, Sakamoto K and Nagaoka I: Glucosamine downregulates the IL-1beta-induced expression of proinflammatory cytokine genes in human synovial MH7A cells by O-GlcNAc modification-dependent and -independent mechanisms. PLoS One 11: e0165158, 2016

25. Barnes PJ and Karin M: Nuclear factor-kappaB: A pivotal transcription factor in chronic inflammatory diseases. N Engl J Med 336: 1066-1071, 1997.

26. Kyriakis JM and Avruch J: Mammalian MAPK signal transduction pathways activated by stress and inflammation: A 10-year update. Physiol Rev 92: 689-737, 2012.

27. Tak PP and Firestein GS: NF-kappaB: A key role in inflammatory diseases. J Clin Invest 107: 7-11, 2001.

28. Hamalainen M, Nieminen R, Vuorela P, Heinonen M and Moilanen E: Anti-inflammatory effects of flavonoids: genistein, kaempferol, quercetin, and daidzein inhibit STAT-1 and NF-kappaB activations, whereas flavone, isorhamnetin, naringenin, and pelargonidin inhibit only NF-kappaB activation along with their inhibitory effect on iNOS expression and NO production in activated macrophages. Mediators Inflamm 2007: 45673, 2007.

29. Weber A, Wasiliew P and Kracht M: Interleukin-1 (IL-1) pathway. Sci Signal 3: $\mathrm{cm} 1,2010$

30. Kawai T and Akira S: TLR signaling. Semin Immunol 19: 24-32, 2007.

31. Zandi $\mathrm{E}$ and Karin M: Bridging the gap: Composition, regulation, and physiological function of the IkappaB kinase complex. Mol Cell Biol 19: 4547-4551, 1999.

32. Zandi E, Chen Y and Karin M: Direct phosphorylation of IkappaB by IKKalpha and IKKbeta: Discrimination between free and NF-kappaB-bound substrate. Science 281: 1360-1363, 1998.

33. Sabio G and Davis RJ: TNF and MAP kinase signalling pathways. Semin Immunol 26: 237-245, 2014.

34. Georganas C, Liu H, Perlman H, Hoffmann A, Thimmapaya B and Pope RM: Regulation of IL-6 and IL-8 expression in rheumatoid arthritis synovial fibroblasts: The dominant role for NF-kappa B but not C/EBP beta or c-Jun. J Immunol 165: 7199-7206, 2000.

35. Saccani S, Pantano S and Natoli G: p38-Dependent marking of inflammatory genes for increased NF-kappa B recruitment. Nat Immunol 3: 69-75, 2002.

36. Hoffmann E, Dittrich-Breiholz O, Holtmann H and Kracht M Multiple control of interleukin- 8 gene expression. J Leukoc Biol 72: 847-855, 2002.

37. Hoffmann E, Thiefes A, Buhrow D, Dittrich-Breiholz O, Schneider H, Resch K and Kracht M: MEK1-dependent delayed expression of Fos-related antigen-1 counteracts c-Fos and p65 NF-kappaB-mediated interleukin- 8 transcription in response to cytokines or growth factors. J Biol Chem 280: 9706-9718, 2005.

38. Srirangan S and Choy EH: The role of interleukin 6 in the pathophysiology of rheumatoid arthritis. Ther Adv Musculoskelet Dis 2: $247-56,2010$

39. Takahashi A, de Andres MC, Hashimoto K, Itoi E and Oreffo RO: Epigenetic regulation of interleukin-8, an inflammatory chemokine, in osteoarthritis. Osteoarthritis Cartilage 23: 1946-1954, 2015. 